DE

M E D I C I N A

T R O P I C A L

$\mathrm{DE}$

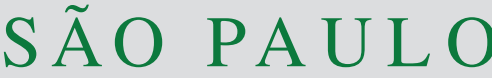

JOURNAL OF THE SÃO PAULO INSTITUTE OF TROPICAL MEDICINE

${ }^{1}$ Hospital "Dr. Marta T. Schwarz", Laboratorio de Análisis Clínicos, Puerto Iguazú,

Misiones, Argentina

${ }^{2}$ Universidad Miguel Hernández de Elche, Área de Parasitología, Alicante, Spain

${ }^{3}$ Universidad Nacional de Misiones, Facultad de Ciencias Exactas, Químicas y Naturales, Departamento de Microbiología, Misiones, Argentina

${ }^{4}$ Universidad Miguel Hernández de Elche, Departamento de Medicina Clínica,

Alicante, Spain

Correspondence to: José Manuel Ramos Rincón

Universidad Miguel Hernández de Elche, Departamento de Medicina Clínica, Campus Sant Joan d'Alacant, 03550, Alicante, Spain

E-mail: jramosrincon@yahoo.es

Received: 9 September 2019

Accepted: 3 February 2020

\section{Syphilis and HIV infection in indigenous Mbya Guarani communities of Puerto Iguazu (Argentina): diagnosis, contact tracking, and follow-up}

\author{
Javier Marx ${ }^{1}$, Lucrecia Acosta ${ }^{\circledR 2}$, Enrique J. Deschutter ${ }^{2}$, Fernando J. \\ Bornay-Llinares ${ }^{3}$, Víctor Sotillo-Soler ${ }^{3}$, José M. Ramos-Rincón ${ }^{\circledR} 4$
}

\section{ABSTRACT}

The aim of study was to assess the prevalence of Treponema pallidum and HIV infection in Amerindian people (Mbya Guarani) over the age of 11 in Puerto Iguazu (Argentina) and to describe the contact tracking of cases. The method was a cross-sectional study in the Mbya Guarani people living in three villages of Puerto Iguazu (community A, pop. 1,146; community B, pop. 369; and community C, pop. 149). Participants were randomly invited to participate in the survey and in blood testing. Of the 551 participants, 48 were infected by T. pallidum (8.71\%; 95\% confidence interval [CI] 7.38-10.04). The infection prevalence decreased with age, standing at $9.66 \%$ in the $11-19$ age group, $8.42 \%$ in $20-39$ age group and $4.54 \%$ in people aged 40 and older. We tracked 130 contacts for the 48 T. pallidum cases; $39 / 40(97.5 \%)$ sexual contacts tested positive for syphilis. Among the 90 children born to infected mothers, 76 aged 18 months or older tested negative, while 8/14 younger children were still at risk for congenital syphilis. There were four cases of HIV infection $(0.72 \%$, 95\% CI 0.31-1.13). Prevalence of T. pallidum infection and HIV infection are relevant in this indigenous community of Argentina, representing a public health concern.

KEYWORDS: Syphilis. Treponema pallidum. HIV. Argentina. Guarani ethnicity. Congenital syphilis.

\section{INTRODUCTION}

Recent years have seen an increase in many sexually transmitted infections (STIs) worldwide, but especially in the Americas, with a clear predominance of syphilis. This infection can be efficiently diagnosed and treated, but it continues to be an important global health problem, especially in female sex workers and men who have sex with men ${ }^{1}$. According to World Health Organization (WHO) global estimates for 2016, there were roughly 376 million cases of new infections of the four curable STIs (chlamydia, gonorrhea, trichomoniasis and syphilis) ${ }^{2,3}$, with an estimated 5.6 million new cases of syphilis (including 988,000 in pregnant women). The global syphilis prevalence has been estimated at $0.5 \%^{2,3}$. At the same time, there were approximately 37.9 million people living with HIV at the end of 2018, and 1.7 million of these cases were new infections ${ }^{4}$.

In Argentina, trends in STIs are similar to elsewhere in the world, for example the United Kingdom, with a general rise in incidence of gonorrhea and syphilis ${ }^{5,6}$. The current prevalence of Treponema pallidum infection, the causative bacterium agent of syphilis in the general population of Argentina is unknown, but according to the Ministry of Health, the number of reported cases increased from 3,875 in 2011 
to 11,709 in 2017 , with outbreaks seen in both adults and adolescents across all the socioeconomic classes ${ }^{6}$. A study in couples who underwent prenatal screening in four provinces (Buenos Aires, Cordoba, Mendoza and Santa Fe) showed a prevalence of syphilis of $0.8 \%$, while the prevalence in pregnant women was approximately $1.32 \%{ }^{7}$. Regarding HIV, an estimated 129,000 people are living with the virus, for an overall prevalence of $0.4 \%$, with 5,800 new diagnoses every year ${ }^{5}$. Young people (especially women under 25) are the ones with the highest risk of acquiring an STI in Argentina ${ }^{5}$.

Few reports of syphilis or HIV infection have been reported in Argentine Amerindians. One study carried out in 2017 reported an overall T. pallidum prevalence of $4.2 \%$ in these communities ${ }^{8}$. In the Mbya-Guarani population of Misiones province, the prevalence was estimated at $6.7 \%$ in 2010 and $6.0 \%$ in $2013^{\circ}$. However, no specific information is available on the prevalence of T. pallidum or HIV in people living in the small Guarani villages of Puerto Iguazu (Misiones, Argentina).

The prevalence of syphilis shows important variations in the indigenous populations of South America. In a study carried out in the Peruvian Amazon, 1.6\% of pregnant indigenous women were infected ${ }^{10}$, while in other communities in the same region, the rates ranged from $3.2 \%$ to $7.5 \%{ }^{11,12}$. In Brazil, the overall prevalence of syphilis was less than $2 \%$, similar to the $1.82 \%$ observed in the indigenous population of the Brazilian State of Amazonas ${ }^{13,14}$, while in Paraguay, the prevalence in the indigenous population is about $6.6 \%{ }^{15,16}$. Likewise, HIV shows variable prevalence rates among indigenous people, estimated at $0.2 \%-0.7 \%$ in the Peruvian Amazon ${ }^{10,12}, 0.25 \%$ in Paraguay ${ }^{15}$, and $0.13 \%-0.80 \%$ in Brazil ${ }^{13,17,18}$.

The aim of this study was to assess the seroprevalence of T. pallidum and HIV infections in residents aged 11 years and older, in the Amerindians communities of Puerto Iguazu. Secondary goals were to describe contact tracking the horizontal transmission (sexual partners) and the vertical one (children of positive mothers) and to assess response to the treatment of syphilis.

\section{METHODS}

A cross-sectional descriptive study of seroprevalence for syphilis and HIV was conducted in three Mbya Guarani communities (villages) in Puerto Iguazu, province of Misiones, Argentina (Figure 1).

\section{Study population}

In this country, the total population of Amerindians in 2010 was 955,032 people, spread across 30 different

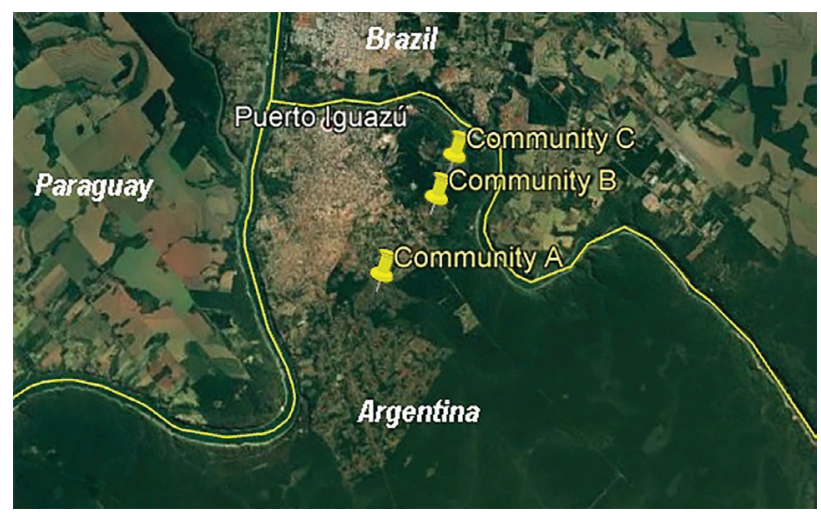

Figure 1 - Geographical location of the Guarani communities in Puerto Iguazu (community A, community B, and community C ).

ethnic groups; together, they make up about $2.4 \%$ of the population ${ }^{19}$. In Misiones, 93 Mbya Guarani communities are dispersed throughout the province, representing more than 1,200 families and a total population of about 6,200 people $^{20}$.

The indigenous population of Puerto Iguazu is made up of approximately 1,600 inhabitants, distributed among three communities (community A, population 1,146, 182 families; community B, population 369, 73 families; community C, population 149, 42 families). All of them are in the peri-urban area of Puerto Iguazu, within a $7 \mathrm{~km}$ radius of "Dr. Marta T. Schwarz" Public Hospital (Figure 1). This population group is not an active part of the health system, nor do its members tend to spontaneously access health services, except in the case of illness or possible pregnancy among young women. Men generally do not use health services. The communities are composed of a large number of families living in small huts, often with two or even three families per dwelling. A small proportion of the Mbya Guarani are semi-nomadic. Culturally speaking, the size of the community is associated with power and social status, so fertility is highly valued, and contraceptives are not socially acceptable. There is little awareness of STIs or the methods used to detect, treat, or prevent them, as health education strategies for preventing STIs have not been culturally designed for these communities.

Regarding the economic context, subsistence activities have been diversified and traditional work, such as hunting, fishing, foraging and slash-and-burn agriculture have been complemented by artisan markets located in different urban settings, as well as temporary jobs in rural colonies. Mbyas enter the broader labor market as part-workers on plantations cultivating yerba mate, tobacco and tea, or as gardeners or carpenters in urban areas. These activities have favored an increased contact with the conventional Argentinian society and a wider use of currency in economic exchanges. This shift has brought about numerous lifestyle changes, creating possibilities for acquiring new goods and 
products, including processed foods, among others, and providing access to different health services.

\section{Sampling strategy}

To estimate the prevalence of T. pallidum infection in Mbya Guarani people, we obtained a random sample of people aged 11 years and older and residing in the indigenous communities of Puerto Iguazu. Participants were selected through a stratified random sampling from a population-based registry at each community primary healthcare center, and the number of participants included from each village was proportional to its size (Table 1).

A sample size calculation was based on an estimated prevalence of syphilis of $5.9 \%,{ }^{8}$ a confidence level of $95 \%$, and precision of $2 \%$, with the help of the Epidat 4.1 software (Direccion Xeral de Saude Publica, Xunta de Galicia, Spain). Thus, the total number of individuals needed from each village was: 297 participants in community A, 176 in community B, and 78 in community C. Subsequent contact tracking included all the contacts of the infected people, independently of age or residence in the studied communities.

\section{Detection of T. pallidum infection}

Screening for T. pallidum infection was performed by means of the unheated-serum reagin (USR)-modified Venereal Disease Research Laboratory test (VDRL test; Wiener Lab, Argentina), and diagnosis was confirmed using an enzyme-linked immunosorbent assay (ELISA) containing $\mathrm{p} 15, \mathrm{p} 17$, and $\mathrm{p} 47$ recombinant antigens of T. pallidum, according to manufacturer's instructions (ELISA 4.0. Wiener Lab, Argentina) and the Ministry of Health of Argentina guidelines on STIs and HIV ${ }^{21}$. Participants were considered to have a syphilis infection if they had a reactive non-treponemal test plus subsequent confirmation with a treponemal test, with no previous history of diagnosis or treatment for syphilis ${ }^{21}$.
In infants aged $<18$ months that were born to infected mothers, diagnosis of congenital syphilis was done by analyzing the clinical status and serological results obtained in the mother-child binomial, according to the criteria established by the Ministry of Health of Argentina ${ }^{22}$ and Parker et al. ${ }^{23}$. Moreover, clinical evaluation and complementary studies were performed during the follow-up. The VDRL test was also used to assess the treatment efficacy.

\section{Detection of HIV infection}

The screening test was the particle-agglutination assay using gelatin particles coated with HIV-1 and HIV-2 antigens (SERODIA-HIV 1/2 Fujirebio, Japan). Samples yielding positive or borderline results were subjected to immunochromatography, using as antigens the synthetic peptides gp41 $\mathrm{M}$ and $\mathrm{O}$ of HIV-1 and gp36 of HIV-2 (HIV 1/2 VIKIA, Bio Merieux, France).

When screened samples were reactive to HIV antibodies, the researchers went back to the community in order to collect a second sample within a week of the first contact, and the infection was confirmed by a second ELISA and Western Blot. More specific tests were also undertaken to assess the viral load and to perform flow cytometry so as to determine the CD4+ lymphocyte count (HIV-1 DNA nested-multiplex-PCR, targeting env and gag HIV-1 genes; and COBAS TaqMan HIV-1, version 2.0; Roche Diagnostics, Mannheim, Germany, respectively) according to the protocols of the Ministry of Health of Argentina ${ }^{24}$. These tests were performed by the Biological Institute "Dr. Tomas Peron" Provincial Reference Center for HIV/AIDS and Viral Hepatitis, in Buenos Aires.

\section{Contact tracking}

After identifying seropositive samples for T. pallidum and HIV, we continue to investigate the case contacts. Contact tracking included (1) potential sexual transmission

Table 1 - Characteristics of the Mbya Guaraní communities included in the study and the study participants.

\begin{tabular}{lccc}
\hline Characteristics & \multicolumn{3}{c}{ Community } \\
\cline { 2 - 4 } & Community A & Communiy B & Community C \\
\hline Total population, $\mathrm{N}$ & 1,146 & 369 & 149 \\
Total population aged $\geq 11$ years, $\mathrm{N}(\%)$ & $669(58.3)$ & $261(70.7)$ & $90(60.4)$ \\
Sampling fraction, $\mathrm{N}(\%)$ & $297(44.4)$ & $176(67.4)$ & $78(86.6)$ \\
Median age (years) in the sample & 20 & 23 & 23 \\
Males in the sampling fraction, $\mathrm{N}(\%)$ & $136(45.8)$ & $80(45.45)$ & $37(47.4)$ \\
Male to female sex ratio in the study sample & 0.84 & 0.83 & 0.90 \\
Age range (years) & $11-90$ & $11-84$ & $11-87$ \\
\hline
\end{tabular}


(sexual partners) of people with confirmed infections in the prevalence study and (2) potential vertical transmission (the children born to seropositive mothers), who may have acquired the infection during the pregnancy or the delivery (transplacental transmission, birth canal, respectively) or, in the case of HIV, also during lactation. The case contacts studied were not part of the original sample.

This study required interdisciplinary actions involving community health workers, who served as linguistic facilitators, as well as physicians from the local hospital, laboratory technicians and professionals from other diagnostic support services. The children born to mothers from the sample were included in the study of case contacts. Those with more than 18 months underwent a VDRL test. Younger children born to seropositive mothers were tested by means of several complementary studies, including radiographs, ultrasounds as well as blood and cerebrospinal fluid (CSF) tests. Diagnosis of congenital syphilis was based on a combination of results from physical, radiological and serological tests on the infant and the mother, in accordance with guidelines on prevention and treatment of congenital and perinatal infections from the Ministry of Health of Argentina $^{21}$. Contacts were tested by means of the same serological laboratory techniques described above, along with additional tests when necessary: polymerase chain reaction (PCR) tests for $\mathrm{HIV}$ in young ( $<18$ months) children, plus reagin tests in CSF.

\section{Assessment of response to treatment}

Individuals whose laboratory tests were positive for syphilis, were informed on their results and offered a fast-track access to treatment. The health professionals team providing services in these communities participated in these activities, performing clinical evaluations and prescribing antibiotic treatment. The treatment used was penicillin benzathine according to the age and weight of the individuals. In patients older than 18 months, treatment efficacy was evaluated at three months after initiating the therapy, using a semiquantitative VDRL laboratory test on a new blood sample, with the same reagents and procedure described above. For syphilis, we defined an adequate serological response and treatment efficacy as a 2-titer decrease on the VDRL at three months of treatment initiation. People falling short of a decrease of 2 titers were considered for a second course of treatment, and the VDRL was repeated at six months. Treatment failure was defined as the cases in which titers either increased or did not change in the nontreponemal test.

The children under 18 months born to mothers with a confirmed infection and suspected of congenital syphilis were treated with crystallin penicillin 100,000-150,000 IU/kg for 10 days. Treatment response was evaluated through laboratory tests and medical examinations with follow-up at three and six months of treatment initiation or until the child reached 18 months of age. An effective response was defined as a negative result or substantial decrease in the VDRL titers, criteria in line with those suggested by the Ministry of Health ${ }^{24}$.

\section{Statistical analysis}

Using data from the prevalence study on syphilis and HIV infection, the variables of the sampled population were compared using the chi-squared test, applying the Yate's correction, when appropriate. The SPSS statistical software (version 16.0, SPSS Inc., Chicago, IL, USA) was used for all the calculations. The magnitude of the effect was quantified as an odds ratio (OR) with a $95 \%$ confidence interval (CI). The two-tailed significance level for all statistical tests was set at $\mathrm{p}<0.05$.

\section{Ethical aspects}

The research project and all the protocols were reviewed and approved by the steering committee of the School of Exact, Chemical and Natural Sciences of the National University of Misiones (Provision No 2171 de 16/12/2014), and by the Ethics Committee of the "Dr. Fernando Barreyro" Public Provincial Pediatric Hospital of Misiones.

Authorization was requested and granted by the caciques (a term used to designate the community leaders) to carry out our research in the villages. All the study participants went through a process of informed consent, in which they received information on the voluntary nature of their participation and could read, ask questions, and receive straightforward answers about the study objectives and the procedures that would be carried out. Furthermore, the health authorities and caciques collaborated on establishing culturally sensitive methods that would enable the fulfilment of both, the study objectives and the respect to the social norms of each community.

\section{RESULTS}

Table 1 describes the study population in the three studied Mbya Guarani communities.

\section{Seroprevalence of T. pallidum infection}

From the total of 551 individuals screened in the three villages, 48 were infected with T. pallidum (seroprevalence 
8.71\%, 95\% confidence interval [CI] 7.38-10.04). This result was similar in all the three communities: community A, 8.42\% (95\% CI 6.36-10.48), community B, 9.09\% (95\% CI 6.85-11.33), and community C, $8.97 \%$ (95\% CI 6.37-11.20). Results of the semiquantitative VDRL test (frequency and titers), were as follows: community A $6.25 \%,<1: 16$; community B $66.66 \%, 1: 16$ to $1: 32$; and $27.08 \%, \geq 1: 64$ in community $\mathrm{C}$.

Table 2 shows data on the seroprevalence to T. pallidum infection in the overall study sample and in each of the indigenous communities. Seroprevalence was similar in both sexes, but decreased with age, standing at $9.66 \%$ in people aged $11-19$ years, $8.90 \%$ in people aged 20-39 (OR:0.91 95\% CI: $0.49-1.68$ ), and $4.54 \%$ in people aged 40 and older (OR: $0.44,95 \%$ CI: $0.12-1.53)(\mathrm{p}=0.05)$. There were no statistically significant differences in seroprevalences between sexes or age groups in the three studied communities.

\section{T. pallidum-HIV coinfection}

There was one case of T. pallidum-HIV coinfection $(0.18 \%, 95 \%$ CI $0.03-1.02)$, occurring in a woman $(1 / 198$, $0.34 \%$ ) residing in community $\mathrm{A}$.

\section{Contact tracking: T. pallidum}

We examined 130 contacts of the 48 people with a confirmed T. pallidum infection: 40 sexual partners and 90 children born to infected mothers. Figure 2 shows the flow chart for the screening of the contacts. From the total of 40 screened sexual partners, 39 tested positive for the infection (97.5\%) (Table 3).

From the total of 43 women infected with T. pallidum (seroprevalence study [ $\mathrm{n}=26$ ] plus contact tracking [n=17]), 38 of them $(88.37 \%)$ had 90 children, whose age ranged from 10 days to 8 years. All the 76 children with more than 18 months old tested negative for syphilis. There were 14 younger children, of whom six were born to mothers who received treatment during pregnancy, and these children tested VDRL negative at birth and at six months of age, so that congenital syphilis was ruled out. The eight remaining children were born at home, and their mothers did not recall having received treatment. All of these children were referred for treatment as well as for laboratory and clinical follow-up until reaching 18 months of age. All the laboratory controls up to 18 months of age showed a reduction in VDRL titers (Table 4). None of the children showed sequelae of congenital disease or signs of late congenital syphilis.

Table 2 - Seroprevalence to T. pallidum and to HIV in the overall study sample and in each indigenous community.

\begin{tabular}{|c|c|c|c|c|c|c|c|c|}
\hline & \multicolumn{2}{|c|}{ Total } & \multicolumn{2}{|c|}{ Community $\mathrm{A}$} & \multicolumn{2}{|c|}{ Community B } & \multicolumn{2}{|c|}{ Community C } \\
\hline & $\mathrm{n} / \mathrm{N}(\%)$ & OR $(95 \% \mathrm{Cl})$ & $\mathrm{n} / \mathrm{N}(\%)$ & OR $(95 \% \mathrm{Cl})$ & $\mathrm{n} / \mathrm{N}(\%)$ & OR $(95 \% \mathrm{Cl})$ & $\mathrm{n} / \mathrm{N}(\%)$ & OR $(95 \% \mathrm{Cl})$ \\
\hline \multicolumn{9}{|c|}{ Treponema pallidum infection } \\
\hline$\overline{\text { Total }}$ & $48 / 551(8.71)$ & - & $25 / 297(8.42)$ & - & $16 / 176(9.09)$ & - & $7 / 78(8.97)$ & - \\
\hline \multicolumn{9}{|l|}{ Sex } \\
\hline Male & $22 / 253(8.69)$ & Ref & 10/136 (7.35) & Ref & $8 / 80(10.00)$ & Ref & 4/37 (10.81) & Ref \\
\hline Women & 26/298 (8.72) & $1.00(0.55-1.81)$ & $15 / 161(9.31)$ & $1.29(0.56-2.98)$ & 8/96 (8.33) & $0.81(0.29-2.28)$ & $3 / 41(7.31)$ & $0.65(0.13-3.12)$ \\
\hline \multicolumn{9}{|l|}{ Age group } \\
\hline $11-19$ years & $23 / 238(9.66)$ & Ref & 12/139 (8.63) & Ref & $7 / 69(10.14)$ & Ref & 4/30 (13.33) & Ref \\
\hline 20 - 39 years & $22 / 247$ (8.90) & $0.91(0.49-1.68)$ & $11 / 139(7.91)$ & $0.90(0.39-2.13)$ & 9/77 (11.69) & $1.17(0.41-3.33)$ & $2 / 31(6.45)$ & $0.44(0.07-2.65)$ \\
\hline$\geq 40$ years & $3 / 66(4.54)$ & $0.44(0.12-1.53)$ & 2/19 (10.52) & $1.25(0.25-6.04)$ & $0 / 30(0.00)$ & NA & $1 / 17(5.88)$ & $0.40(0.04-3.93)$ \\
\hline \multicolumn{9}{|l|}{ Range of titers } \\
\hline $1: 2-1: 8$ & $3 / 48(6.25)$ & - & $2 / 25(8.00)$ & - & $1 / 16(6.25)$ & - & $0 / 7(12.50)$ & - \\
\hline $1: 16-1: 32$ & $32 / 48(66.66)$ & - & $11 / 25(44.00)$ & - & $14 / 16(87.50)$ & - & $7 / 7(8.75)$ & - \\
\hline $1: 64-1: 128$ & $13 / 48(27.08)$ & - & $12 / 25(48.00)$ & - & $1 / 16(6.25)$ & - & $0 / 7(0.00)$ & - \\
\hline \multicolumn{9}{|l|}{ HIV infection } \\
\hline Total & $4 / 551(0.72)$ & & $2 / 297(0.67)$ & & $2 / 176(1.13)$ & & $0 / 78(0.00)$ & \\
\hline \multicolumn{9}{|l|}{ Sex } \\
\hline Male & $1 / 253(0.39)$ & Ref & $0 / 136(0.00)$ & Ref & $1 / 80(1.25)$ & Ref & $0 / 37(0.00)$ & Ref \\
\hline Women & $3 / 298(1.00)$ & $2.56(0.26-24.8)$ & 2/161 (1.24) & NA & $1 / 96(1.09)$ & $0.83(0.05-13.5)$ & $0 / 41(0.00)$ & NA \\
\hline \multicolumn{9}{|l|}{ Age group } \\
\hline $11-19$ years & 0/238 (0.00) & NA & 0/139 (0.00) & NA & $0 / 69(0.00)$ & NA & $0 / 30(0.00)$ & NA \\
\hline 20 - 39 years & $3 / 247(1.21)$ & $0.79(0.08-7.81)$ & $1 / 139(0.71)$ & $0.13(0.01-2.17)$ & 2/77 (2.59) & NA & $0 / 31(0.00)$ & NA \\
\hline$\geq 40$ years & $1 / 66(1.51)$ & Ref & $1 / 19(5.26)$ & Ref & $0 / 30(0.00)$ & Ref & $0 / 17(0.00)$ & Ref \\
\hline
\end{tabular}

n: number of events; N: sample size; NA: not available; Ref: reference; OR: odds ratio; $95 \% \mathrm{Cl}$ : confidence interval 


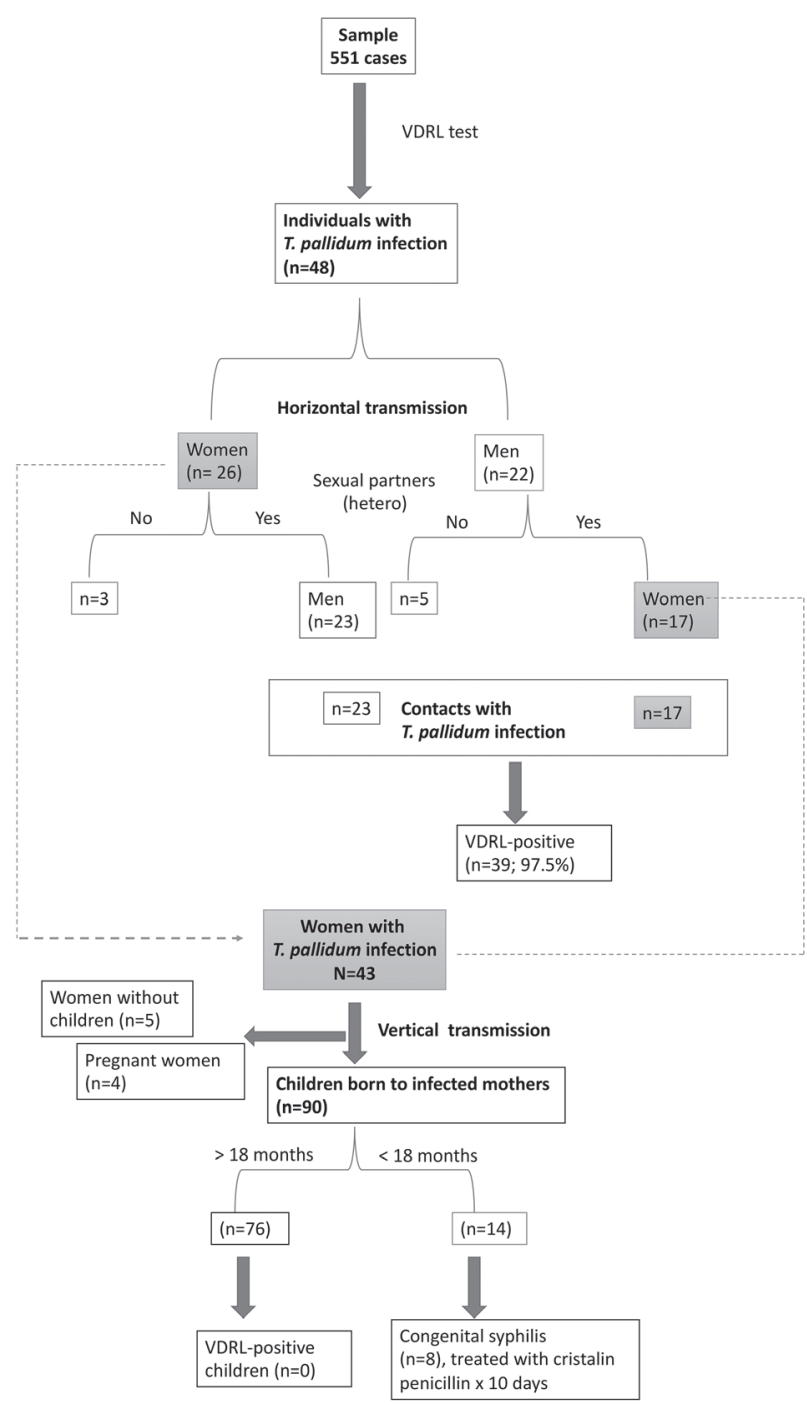

Figure 2 - Flow chart of the 551 study participants and case contacts (horizontal transmission and vertical transmission).

\section{Response to treatment}

Between the prevalence study and the case contacts tracking, a total of 95 individuals were diagnosed with T. pallidum infection. They were divided into two groups according to age: group 1 consisted of 8 children younger than 18 months, and group 2 was composed of 87 adolescents and adults aged 11 years and older. All the young children completed the indicated treatment, as prescribed, and then showed negative results in the VDRL test. In the second group, $97.7 \%$ (85/87) were treated, while two individuals $(2.3 \%$ ) could not be found and thus did not receive treatment. Of these 85 people, 82 (96.5\%) completed the treatment, while the other three received only one dose of the antibiotic. Health workers were unable to find them to administer the remaining medication. Likewise, two of the people who completed the treatment were lost to followup before their treatment response could be assured by the VDRL test; the other 80 patients were tested.

Based on medical and laboratory criteria, treatment was considered effective in all of the group 1 patients at 3and 6-months follow-ups. At 18 months of age, they were tested again to confirm the seronegative result. A decrease in VDRL titers was observed in all the patients in group 2, with a drop of two or more dilutions in the reaction, showing that the treatment was effective.

All of the children over 18 months $(n=76)$ tested negative, indicating that the mother's infection was recent or there was no vertical transmission. The 14 children aged less than 18 months were clinically and laboratory evaluated and their mothers' medical histories were reviewed. All of the mothers with confirmed syphilis at the time of the study and who had given birth in the hospital they were treated, had babies that tested negative on the first followup VDRL. That is, congenital syphilis was ruled out in six infants on the first visit. The remaining eight infants, who were born at home, were considered probable cases of congenital syphilis. Subsequent VDRL tests showed a decrease in the reaction titers. These results, taken together with the complementary studies, showed the efficacy of the antibiotic treatment administered. None of the children presented sequelae of congenital disease or manifestations of late congenital syphilis.

\section{HIV infection}

Four people were infected with HIV (0.72\%, 95\% CI 0.31-1.13): two participants from the community A $(0.67 \%, 95 \%$ CI $0.15-1.19)$ and two from the community B (1.14\%, 95\% CI 0.28-2.00). Three were women (1.00\%) and one was a man $(0.39 \%)$. None of the cases were in the 11-19 age group; three were aged 20 - 39 years (1.21\%),

Table 3 - Sexual partners from the T. pallidum seroprevalence study.

\begin{tabular}{|c|c|c|c|}
\hline & $\begin{array}{l}\text { Men } \\
\mathrm{n}(\%)\end{array}$ & $\begin{array}{c}\text { Women } \\
\mathrm{n}(\%)\end{array}$ & $\begin{array}{l}\text { Total } \\
\text { N (\%) }\end{array}$ \\
\hline T. pallidum infection confirmed by the seroprevalence study & $22(45.9)$ & $26(54.1)$ & $48(100)$ \\
\hline Sexual partners identified during contact tracking & $23(57.5)$ & $17(42.5)$ & $40(100)$ \\
\hline Positive T. pallidum infection in sexual partners & $22(95.6)$ & $17(100)$ & $39(97.5)$ \\
\hline
\end{tabular}


Table 4 - Serological follow-up of the 14 children born to mothers with T. pallidum infection.

\begin{tabular}{|c|c|c|c|c|c|c|c|c|}
\hline $\begin{array}{l}\text { Patient } \\
\text { code }\end{array}$ & $\begin{array}{c}\text { Age } \\
\text { (months) }\end{array}$ & $\begin{array}{l}\text { Previous } \\
\text { treatment for } \\
\text { syphilis in the } \\
\text { mother }\end{array}$ & Birthplace & $\begin{array}{l}\text { VDRL titers in } \\
\text { the mother }\end{array}$ & $1^{\text {st }}$ follow-up & $\begin{array}{l}\text { Treatment in } \\
\text { the child }\end{array}$ & $2^{\text {nd }}$ follow-up & $\begin{array}{l}3^{\text {rd }} \text { follow-up } \\
(6 \text { months })\end{array}$ \\
\hline 1 & 0 & No & Home & 64 & $\mathrm{Neg}$ & Yes & $\mathrm{Neg}$ & $\mathrm{Neg}$ \\
\hline 2 & 3 & No & Home & 64 & 32 & Yes & 8 & 2 \\
\hline 3 & 4 & Yes & Hosp & 32 & Neg & No & - & - \\
\hline 4 & 1 & Yes & Hosp & 16 & Neg & No & - & - \\
\hline 5 & 2 & No & Home & 16 & 16 & Yes & 8 & 2 \\
\hline 6 & 4 & Yes & Hosp & 64 & Neg & No & - & - \\
\hline 7 & 1 & Yes & Hosp & 64 & Neg & No & - & - \\
\hline 8 & 2 & No & Home & 4 & 16 & Yes & 4 & 2 \\
\hline 9 & 1 & No & Home & 16 & 4 & Yes & 2 & Neg \\
\hline 10 & 1 & No & Home & 16 & 16 & Yes & 2 & $\mathrm{Neg}$ \\
\hline 11 & 1 & No & Home & 8 & $\mathrm{Neg}$ & Yes & $\mathrm{Neg}$ & $\mathrm{Neg}$ \\
\hline 12 & 3 & Yes & Hosp & 32 & $\mathrm{Neg}$ & No & - & - \\
\hline 13 & 0 & Yes & Hosp & 64 & Neg & No & - & - \\
\hline 14 & 1 & No & Home & 32 & 32 & Yes & 4 & 2 \\
\hline
\end{tabular}

Neg: negative VDRL result; Hosp: Hospital.

and one was more than 40 years old $(1.51 \%)$. In three of the HIV-positive people, the CD4+ lymphocyte count was greater than 500 cells $/ \mu \mathrm{L}$.

\section{Contact tracking: HIV}

Two of the four HIV-positive individuals from the community B emigrated, so it was not possible to obtain information on their contacts. Considering the two infected women that lived in community A, one did not identify any sexual partner. The other was pregnant and had a current partner, who was also HIV-positive. Two children, aged two and five years old were also evaluated, and they tested negative for HIV.

\section{DISCUSSION}

Our results indicated high seroprevalence to T. pallidum $(8.71 \%)$ in the Mbya Guarani communities of Puerto Iguazu, and we identified four HIV-positive individuals $(0.72 \%)$. Thus, the presence of these diseases, none of which had been diagnosed prior to this study, has been confirmed in the villages surrounding the city of Puerto Iguazu.

The observed seroprevalence to T. pallidum was higher than the $0.8 \%$ reported in a study on the prevalence of syphilis in people undergoing a premarital blood test investigation in Argentina ${ }^{24}$ and the $1.6 \%$ found in females and $6.8 \%$ in males in the region of Rio Cuatro (Cordoba) in a study on STIs ${ }^{8}$. Our population has also shown a higher prevalence than the $1.4 \%$ observed in adolescent mothers in Misiones ${ }^{10}$, the $4.2 \%$ seen in Amerindians in Argentina ${ }^{8}$, and the $6.0 \%{ }^{9}$ to $6.7 \%{ }^{8}$ observed in various Mbya Guarani villages from Misiones Province. On the other hand, prevalence in our study was lower than that observed in high risk populations, including men who have sex with men (20.5\%), female sex workers (22.4\%), and transgender sex workers $(50 \%)^{25-27}$.

In general, Amerindian populations maintain their cultural and social customs but remain economically, politically and socially excluded ${ }^{28,29}$. The factors most closely associated with syphilis and HIV infections in Amerindians are polygamy, multiple sexual partners, transactional sex (exchanging sex for money, goods, or other needs), high population mobility, and presence of and relationships with colonizers, among others ${ }^{16,18,30}$. In addition, economic, geographic and cultural barriers prevent regular access to basic health services, affecting the frequency of STI testing and treatment ${ }^{16,18,30}$. These populations also tend to receive little information on STIs in their own languages ${ }^{16}$. Factors that might explain the higher prevalence of syphilis in these indigenous communities, in comparison to the general population, include the beliefs on health and sickness among the Mbya Guarani population; the use of traditional medicine as the first option to deal with a health problem; the continuous migration of community members, complicating the health 
system's capacity to detect, treat, and follow them; the negligible presentation of men to healthcare services (most indigenous people presenting to health centers are women giving birth, although most births are at home); the long distance $(10 \mathrm{~km})$ separating the communities and health centers with laboratory services to detect these diseases; sociocultural characteristics such as the non-acceptance of barrier contraception methods (condoms) during sexual intercourses; the lack of sexual health promotion professionals working as linguistic and cultural facilitators; and the lack of general health promotion, as well as STI prevention, adapted to the Mbya Guarani population.

In addition, the low acceptance of barrier contraception methods occurs in a context where many people have multiple sexual partners, further increasing the risk of STIs. Another peculiarity that would favor transmission is the small proportion of Mbyas who maintain a semi-nomadic lifestyle, whereby individuals or small families moving between different Mbya Guarani settlements in Misiones, Brazil, and Paraguay. This mobility would also facilitate the transmission of STIs between communities ${ }^{16}$.

A final and relevant risk of transmission is the increased contact with the wider Argentinian population through the labor market, for example when Mbyas work during the harvest season on yerba mate, tobacco and tea plantations or in urban areas as gardeners or carpenters. All of these activities favor a more intense contact and disassortative mixing of populations, favoring the transmission of STIs ${ }^{31}$.

The prevalence results are representative of the three included villages around Puerto Iguazu, but they cannot be generalized to all Mbya Guarani populations, as we do not have information on the epidemiological profile of the other communities in the region. Cultural practices and behaviors in the villages can vary significantly depending on unknown factors, and these could have an important impact considering the villages' locations and their social patterns relative to urban areas of the non-Guarani population. That said, one recent study in Guarani women of Paraguay reported a prevalence of $T$. pallidum infections of $6.8 \%^{18}$ and $6.6 \%{ }^{15}$ in younger (15 to 18 years).

In other indigenous populations of South America, the prevalence of syphilis shows important differences. In a study in pregnant indigenous women of the Peruvian Amazon, the prevalence was $1.6 \%{ }^{10}$, while in other communities in the same region it reached $7.5 \%{ }^{12}$. In the Brazilian Amazon, another study found a prevalence of $1.82 \%{ }^{13}$, with implications for the risk of congenital syphilis ${ }^{14}$.

The constant migration of inhabitants from the villages limited the case follow-up and the cases contact tracking in sexual partners and children. Moreover, it is very likely that the study participants who tested positive for infection did not inform all their sexual partners of the results. The identification of sexual partners and children born to infected mothers was possible for all the people initially screened for T. pallidum. Amerindian women are not used to undergoing prenatal checkups, and the failure to detect and treat syphilitic women is directly associated to an increased risk of congenital syphilis ${ }^{8}$. The two children born to mothers infected with T. pallidum and who had reactive serological tests were delivered at home; these domiciliary births occurred without any pre- or post-natal check-ups.

Congenital syphilis is a serious condition, and its prevalence is not unimportant in the indigenous population $^{2,8,14}$. In our study, all the children older than 18 months $(\mathrm{n}=76)$ tested negative, suggesting that the infections were recent or there was no vertical transmission. The 14 children of less than 18 months of age were assessed clinically and through blood tests. The children at risk of congenital syphilis, including those whose mothers received prenatal care and birth assistance at the hospital and those treated later, did not show any sequelae of congenital disease or signs of late congenital syphilis.

The positivity of HIV was $0 \%$ in the community C, $0.67 \%$ in the community $\mathrm{A}$, and $1.14 \%$ in the community $\mathrm{B}$, for a total prevalence $0.72 \%$. These results are difficult to compare with other reports, since there is little data on HIV seroprevalence in Argentina. A few studies were performed in pregnant women and in high-risk populations ${ }^{5}$. A single study in Argentine Amerindians found no cases of HIV ${ }^{8}$. Of the four seropositive individuals, the CD4+ lymphocyte count was more than 500 cells $/ \mu \mathrm{L}$ in three cases, indicating that the immunodepression related to HIV was not severe.

In the 10 years preceding our study, data on pregnant women have shown a decline in HIV infection, with prevalence of less than $0.5 \%$. In the general population, estimates based on screening of pregnant women have also suggested that prevalence is less than $1 \%$. In some specific groups it is much higher, for example, $30 \%$ among transgender people, $12 \%$ in men who have sex with men, $7 \%$ in intravenous drug users, and $6 \%$ in sex workers ${ }^{5,32}$. On the other hand, the prevalence of HIV in Amerindian populations of South America is variable. In the Peruvian Amazon, it ranges from $0.2 \%-0.7 \%{ }^{10,11}$, compared to $0.25 \%$ in Paraguay ${ }^{15}$, and $0.13 \%-0.80 \%$ in Brazil ${ }^{13,17,18}$.

The present study does show that these diseases are present in these Amerindian communities. Considering the conditions of social vulnerability to which these collectives are subject, it is possible that serious health consequences could affect Mbya Guarani villages in the short term.

There is little available information on health in Amerindians in Argentina, and even less in the area of 
sexual and reproductive health ${ }^{8,10,22}$. However, there is published evidence on the high rates of pregnancy in adolescence, the lack of sexual education, and the presence of STIs, as indicated by studies of human papilloma virus $(\mathrm{HPV})^{18}$. Different interventions have been implemented to improve indigenous health. The National Institute of Indigenous Affairs (INAI in its Spanish abbreviation), created by Act 23.302, aimed to address the inequalities that exist between these populations and the general population of Argentina ${ }^{32}$. Moreover, in the 1990s, the National Support Program of Humanitarian Actions for Indigenous Peoples (ANAHI in its Spanish abbreviation) established posts for indigenous community health workers who act as intermediaries between traditional cultures in the villages and the National Health System of Argentina ${ }^{33}$.

Our results on the prevalence of HIV and syphilis in these communities, along with the associated disease burden and risks, highlight the need for timely and appropriate intervention in the most vulnerable groups. Communitybased measures could include the promotion of spaces for learning and empowerment, as well as the use of statistical data by indigenous peoples to illustrate and address their needs and opportunities. The State could also strengthen its public policies to promote, develop, and implement continuous, standing educational opportunities, devoted primarily to the most vulnerable linguistic families. These health promotion activities could take place in both schools and in other settings.

In the healthcare system, another method would be to create primary care centers within each community with doctors, nurses, and health promotion workers, as well as medical brigades to offer additional screening and treatment services. Better monitoring and integration of community members within the health system is also necessary to provide appropriate diagnosis, treatment, and follow-up services. Proper prenatal care with thorough checkups in each trimester, along with rigorous contact tracking in people diagnosed with infectious diseases, are also necessary, maintaining the utmost respect for local cultural rules.

One limitation of this study is that the sample size was calculated based on an estimated prevalence of syphilis of $5.9 \%$, a confidence level of $95 \%$, and precision of $2 \%$. This calculation did not consider the estimated prevalence of HIV, so the prevalence of HIV was underestimated in relation to the sample size used. Another limitation was the non-inclusion of variables that could have provided information on risk factors for seropositivity to T. pallidum and HIV, such as polygamy, sexual intercourse, multiple sexual partners, transactional sex, nomadic or semi-nomadic behaviors, and the presence of and relationships with the conventional Argentinian society.

\section{CONCLUSION}

Despite the methodological limitations, and considering the epidemiological data available for the territory of Argentina, our results suggest that prevalence of $T$. pallidum infection and HIV infection are relevant in this indigenous community of Argentina, representing a public health concern. This is consistent with the context of social vulnerability and exclusion that characterizes these indigenous communities ${ }^{34}$.

Our results suggest that it is necessary to increase the provision of different health services for these populations, including health promotion. Primary care centers could offer rapid diagnostic tests and treatments for STIs, while a medical brigade could offer additional screening and treatment.

\section{ACKNOWLEDGMENTS}

We thank all the members of the laboratory staff at the "Dr. Marta T. Schwarz" Public Hospital, Puerto Iguazu, Misiones, Argentina. Special mention goes to Meggan Harris for the translation and editing of the manuscript. This study is part of a master thesis in Public Health and Infectious Diseases, at the School of Exact, Chemical and Natural Sciences, National University of Misiones, Posadas, Misiones, Argentina.

\section{AUTHORS' CONTRIBUTIONS}

JM, FBL, and EJD provided institutional support and coordinated the study; JM and FBL designed the study; JM and VSS are part of the team responsible for supervising the field work; JM, LAS and JMRR analyzed the data and wrote the manuscript. All the authors interpreted the data, critically reviewed the manuscript for important intellectual content and gave their final approval for this version to be published.

\section{CONFLICT OF INTERESTS}

The authors declare that they have no competing interests

\section{FUNDING}

This work was supported by the Ministry of Public Health, Misiones Argentina, the Pan American Health Organization (TDR/UNICEF/UNDP/WB/WHO, Ref. A-1266-2014), and the Regional Government of Valencia, Spain (Generalitat Valenciana, Ref. 5009/2013). 


\section{REFERENCES}

1. O’Byrne P, MacPherson P. Syphilis. BMJ. 2019;365:I4159.

2. World Health Organization. Report on global sexually transmitted infection surveillance, 2018. Geneva: WHO; 2018. [cited 2019 Aug 12]. Available from: https://apps.who.int/iris/bitstream/ha ndle/10665/277258/9789241565691-eng.pdf?ua=1

3. Newman L, Rowley J, Vander Hoorn S, Wijesooriya NS, Unemo $\mathrm{M}$, Low N, et al. Global estimates of the prevalence and incidence of four curable sexually transmitted infections in 2012 based on systematic review and global reporting. PLoS One. 2015;10:e143304.

4. World Health Organization. HIV/AIDS: key facts. [cited 2019 Aug 12]. Available from: https://www.who.int/news-room/ fact-sheets/detail/hiv-aids

5. Mohammed H, Blomquist P, Ogaz D, Duffell S, Furegato M, Checchi M, et al. 100 years of STIs in theUK: a review of national surveillance data. Sex Transm Infect. 2018;94:553-8.

6. Argentina. Ministerio de Salud. Sífilis congénita. Bol Integr Vigil. 2017;356:81

7. Fondo de las Naciones Unidas para la Infancia. VIH y sífilis: seroprevalencia en puérperas de Argentina. Buenos Aires: UNICEF; 2012. [cited 2019 Aug 12]. Available from: http:// www.msal.gob.ar/sida/images/stories/4-publicaciones/ pdf/2013-09_VIH_Sifilis_Web.pdf

8. Eirin ME, Delfino CM, Pedrozo WR, Malan R, Puca A, De Rissio AM, et al. Health care importance of Treponema pallidum, Chagas' disease and Human immunodeficiency virus 1 among Amerindians of Argentina: an observational study. Rev Argent Microbiol. 2017;49:315-9.

9. Bornay-Llinares FJ, Pedrozo WR, Galarza F, Piragine RC, Roginski S, Malvasi G, et al. Syphilis in the Mbya-Guaraní population of Misiones (Argentina): evidence proves the need to design and implement a scheduled intervention. Sex Transm Dis. 2014;41 Suppl 1:S85.

10. Ormaeche M, Whittembury A, Pun M, Suárez-Ognio L. Hepatitis $B$ virus, syphilis, and HIV seroprevalence in pregnant women and their male partners from six indigenous populations of the Peruvian Amazon Basin, 2007-2008. Int J Infect Dis. 2012;16:e724-30.

11. Bartlett EC, Zavaleta C, Fernández C, Razuri H, Vilcarromero $\mathrm{S}$, Vermund SH, et al. Expansion of HIV and syphilis into the Peruvian Amazon: a survey of four communities of an indigenous Amazonian ethnic group. Int J Infect Dis. 2008;12:e89-94.

12. Zavaleta C, Fernández C, Konda K, Valderrama Y, Vermund SH, Gotuzzo E. High prevalence of HIV and syphilis in a remote native community of the Peruvian Amazon. Am J Trop Med Hyg. 2007;76:703-5.

13. Benzaken AS, Sabidó M, Brito I, Bermúdez XP, Benzaken NS, Galbán E, et al. HIV and syphilis in the context of community vulnerability among indigenous people in the Brazilian Amazon. Int J Equity Health. 2017;5;16:92.

14. Tiago ZD, Picoli RP, Graeff SV, Cunha RV, Arantes R. Underreporting of gestational, congenital and acquired syphilis among indigenous peoples in Mato Grosso do Sul State, Brazil, 2011-2014. Epidemiol Serv Saude. 2017;26:503-12.

15. Ortiz A, Estigarribia G, Aguilar G, Espinosa Miranda A, McFarland W, Ríos-González CM, et al. Prevalencia de sífilis y características del comportamiento de los jóvenes indígenas del Paraguay, 2016. Mem Inst Investig Cienc Salud. 2018;16:51-7.

16. Aguilar G, Estigarribia G, Ortiz A, Miranda AE, McFarland W, Kawabata A, et al. Prevalence of syphilis and related risk behaviors among women in five distinct indigenous populations in Paraguay. Sex Transm Dis. 2019;46:246-9.

17. Oliveira RS, Benzaken AS, Saraceni V, Sabidó M. HIV/AIDS epidemic in the State of Amazonas: characteristics and trends from 2001 to 2012. Rev Soc Bras Med Trop. 2015;48 Suppl $1: 70-8$

18. Aguilar G, Estigarribia G, Giménez L, Samudio T, Kawabata A, Lopez G, et al. Prevalencia de VIH y sífilis y conocimientos, prácticas y actitudes de la población indígena según familias lingüísticas en el Paraguay: 2016. Asunción: Ministerio de Salud Publica y Bienestar Social; 2016. [cited 2019 Aug 12]. Available from: http://onusidalac.org/1/images/informeEstudio-indigenas-paraguay2016.pdf

19. Argentina. Instituto Nacional de Estadística y Censos. Censo Nacional de Población, Hogares y Viviendas 2010: censo del bicentenario: pueblos originarios: región Pampeana. Buenos Aires: INDEC; 2015. [cited 2019 Aug 12]. Available from: http://trabajo.gob.ar/downloads/pueblosindigenas/pueblos_ originarios_Pampeana.pdf

20. Misiones. Ministerio de Salud Pública. Programas comunitarios APS: Techay Mbya: salud indígena. [cited 2019 Aug 12]. Available from: https://salud.misiones.gob.ar/programascomunitarios-de-aps-techai-mbya-salud-indigena/

21. Bouzas MB, Cudola A, Salomón H. Propuesta de nuevos algoritmos de diagnóstico de VIH. Buenos Aires: Ministerio de Salud; 2013. [cited 2019 Jan 1]. Available from: http://www. msal.gob.ar/sida/images/stories/5-comunicacion/pdf/201403_propuesta-nuevos-algoritmos.pdf

22. Garcia F, Vázquez L, Sarubbi MA. Guía de prevención y tratamiento de las infecciones congénitas y perinatales. Buenos Aires: Ministério de Salud; 2010. [cited 2019 Aug 12]. Available from: http://www.msal.gob.ar/images/stories/bes/ graficos/0000000316cnt-g10-guia-infecciones-perinatales.pdf

23. Parker LA, Deschutter EJ, Bornay-Llinares FJ, Hernandez-Aguado I, Silva G, Piragine RC, et al. Clinical and socioeconomic determinants of congenital syphilis in Posadas, Argentina. Int J Infect Dis. 2012;16:e256-61

24. Angeleri P, Levite V, Vidiella G, Solari J, Coronel E, Adaszko D, et al. Viral hepatitis and Treponema pallidum prevalence in 
persons who underwent premarital blood tests in Argentina. Sci Rep. 2019;9:9611.

25. Pájaro MC, Barberis IL, Godino S, Pascual L, Agüero M. Epidemiology of sexually transmitted diseases in Río Cuarto, Argentina. Rev Latinoam Microbiol. 2001;43:157-60.

26. Pando MA, Balán IC, Marone R, Dolezal C, Leu CS, Squiquera L, et al. HIV and other sexually transmitted infections among men who have sex with men recruited by RDS in Buenos Aires, Argentina: high HIV and HPV infection. PLoS One. 2012;7:e39834.

27. Dos Ramos Farías MS, Garcia MN, Reynaga E, Romero M, Vaulet ML, Fermepín MR, et al. First report on sexually transmitted infections among trans (male to female transvestites, transsexuals, or transgender) and male sex workers in Argentina: high HIV, HPV, HBV, and syphilis prevalence. Int J Infect Dis. 2011;15:e635-40.

28. Bartlett JG, Madariaga-Vignudo L, O'Neil JD, Kuhnlein HV. Identifying indigenous peoples for health research in a global context: a review of perspectives and challenges. Int J Circumpolar Health. 2007;66:287-307.
29. Lorenzetti M. Relaciones interétnicas y prácticas de atención de la salud en el Chaco Salteño. Corpus. 2011:1:1-18.

30. Ehrenberg JP, Ault SK. Neglected diseases of neglected populations: thinking to reshape the determinants of health in Latin America and the Caribbean. BMC Public Health. 2005;5:119.

31. Norris AH, Loewenberg Weisband Y, Wiles M, Ickovics JR. Prevalence of sexually transmitted infections among Tanzanian migrants: a cross-sectional study. Int J STD AIDS. 2017;28:991-1000.

32. Gassman AM, Almada J, Ferreira A, Quiñones S. Sala de situación de salud. Misiones: Ministerio de Salud Pública; 2013. [cited 2019 Jan 1]. Available from: https://salud.misiones.gob.ar/wpcontent/uploads/2017/07/Analisis_de_la_situacion_de_saludcomunidad.pdf

33. Argentina. Instituto Nacional de Asuntos Indígenas. [cited 2019 Jan 1]. Available from: https://www.argentina.gob.ar/ derechoshumanos/inai

34. Enriz N. Identidades en tensión, lo indígena y lo nacional en las experiencias cotidianas mbyá. Polis. 2010;27:1-16. 